\title{
Prognostic significance of serum insulin-like growth factor-1 in patients with hepatocellular carcinoma following transarterial chemoembolization
}

\author{
SHENG LIU, YANHUA LIU and XUEWEN JIANG \\ Department of Interventional Radiology and Nuclear Medicine, Yuhuangding Hospital, \\ Qingdao University, Yantai, Shandong 264000, P.R. China
}

Received October 1, 2014; Accepted September 18, 2015

DOI: $10.3892 / \mathrm{etm} .2015 .2949$

\begin{abstract}
Insulin-like growth factor-1 (IGF-1) is an effective survival factor that is involved in the development and progression of various tumors. The aim of the present study was to investigate whether baseline serum IGF-1 levels are associated with time to progression (TTP) and overall survival (OS) in patients with hepatocellular carcinoma (HCC) who have undergone transarterial chemoembolization (TACE). A total of 145 patients with HCC who underwent TACE as an initial treatment were enrolled in the study. Baseline serum IGF-1 levels were detected using enzyme-linked immunosorbent assay (ELISA) kits. The patients were followed up for a median follow-up period of 47 months (range, 10.6-69.3 months). During the follow-up, 98 patients $(76.6 \%)$ experienced disease progression and 59 patients $(46.1 \%)$ succumbed. The serum IGF-1 level was found to be significantly associated with hepatitis infection status, Child-Pugh class, bilirubin level, tumor size and nodularity, vascular invasion and the Barcelona Clinic Liver Cancer (BCLC) stage. Multivariate analysis was conducted, which indicated that BCLC stage, vascular invasion and serum IGF-1 were independent risk factors for disease progression. When clinical factors were examined as potential independent risk factors for OS, only advanced BCLC stage and low serum IGF-1 levels were found to be significantly associated with poorer OS. These results suggest that serum IGF-1 may serve as a predictor of the prognosis of patients with HCC undergoing TACE.
\end{abstract}

Correspondence to: Professor Xuewen Jiang, Department of Interventional Radiology and Nuclear Medicine, Yuhuangding Hospital, Qingdao University, 20 Yuhuangding East Road, Yantai, Shandong 264000, P.R. China

E-mail: xuewen_jiang@yeah.net

Key words: insulin-like growth factor-1, hepatocellular carcinoma, transarterial chemoembolization, time to progression, overall survival

\section{Introduction}

Hepatocellular carcinoma (HCC) is the fifth most common type of cancer and the third most common cause of cancer-related mortality worldwide. The International Agency for Research on Cancer estimates that 748,300 new cases of liver cancer and 695,900 cancer-related mortalities occur worldwide every year (1). Despite improvements in surgical techniques and perioperative management, as well as the development of non-surgical treatments such as radiofrequency ablation and transarterial chemoembolization (TACE), the prognosis of HCC remains poor due to the advanced tumor stage accompanied by chronic liver disease (CLD) at diagnosis (2). The identification of biomarkers that correlate with the outcome of patients with HCC may be useful in determining the prognosis of this disease, identifying the patients most likely to benefit from particular treatments and assisting clinicians in the design of personalized treatment strategies (3).

Insulin-like growth factor-1 (IGF-1) is a potent survival factor involved in the development and progression of various cancers (4). Studies have suggested that high circulating levels of IGF-1 are associated with increased risk of different types of cancers, such as prostate, breast and colon cancers, due to activation of the downstream cascade of the IGF axis (5-7). However, the association between IGF-1 and HCC is somewhat different from that of other cancers. Since IGF-1 is synthesized primarily by the liver, circulating IGF-1 levels reflect liver function and decrease significantly in patients with hepatitis $\mathrm{C}$ virus infection (8), liver steatosis (9), liver cirrhosis (10), non-alcoholic steatohepatitis (9) and HCC (11). A recent study has demonstrated significant associations between IGF-1 expression and liver cirrhosis and survival following resection in patients with HCC, which is independent from the underlying liver disease (12). Moreover, low baseline serum levels of IGF-1 were found to be associated with low disease control rate and poor progression-free survival and overall survival (OS) of patients with advanced HCC treated with systemic antiangiogenic therapy (13). Furthermore, since HCC is a hypervascular tumor and vascular endothelial growth factor (VEGF)-induced angiogenesis plays a major role in tumor progression and metastasis, TACE is an effective nonsurgical treatment for HCC (14). Therefore, it may be speculated that 
low baseline levels of IGF-1 in the serum may also independently associated with poor outcomes in patients receiving TACE as their initial treatment. Thus, the aim of the present study was to investigate the prognostic value of baseline serum IGF-1 levels in patients with HCC undergoing TACE.

\section{Materials and methods}

Patients. Between May 2007 and June 2011, 145 consecutive patients with HCC who underwent TACE as initial treatment at the Department of Interventional Radiology and Nuclear Medicine, Yuhuangding Hospital (Yantai, China) were enrolled in this study. HCC was reconfirmed in all patients on the basis of the American Association for the Study of Liver Diseases practice guidelines (15). The study inclusion criterion was HCC classified as Barcelona Clinic Liver Cancer (BCLC) stage $\mathrm{B}$ or $\mathrm{C}$, which is generally not regarded as an indication for treatment with curative intent. Patients with early-stage HCC (BCLC stage 0 or A) who were unsuitable for surgical resection or ablation because of liver function, comorbidity or technical infeasibility were also included. Exclusion criteria were extrahepatic metastasis, Child-Pugh class $\mathrm{C}$ and the concurrent presence of another primary liver cancer (such as fibrolamellar HCC or cholangiocarcinoma) or other types of cancers. The study protocol was conducted in accordance with the ethical guidelines of the Declaration of Helsinki and was approved by Institutional Review Board of Yuhuangding Hospital. Written informed consent was obtained from all patients.

TACE procedure. All patients were treated using the same TACE procedure conducted by the same team. Briefly, angiographic examination was performed using a 5-Fr catheter inserted through the femoral artery. Using arteriography, the hepatic or superior mesenteric artery was selected on the basis of tumor arterial blood supply and the tip of the catheter was superselected into the tumor-feeding branches, with the use of a microcatheter if necessary. Once the target tumor-feeding artery had been identified, chemoembolization was achieved as selectively as possible for all targeted lesions in the left and right lobes of the liver with 2-20 ml emulsion comprising cisplatin and lipiodol (1:1). Polyvinyl alcohol or gelatin sponge particles were injected if required to embolize tumor-feeding vessels to guarantee that there was no longer any tumor staining following repeat angiography. Patients were subsequently managed for potential postembolization syndrome (such as fever, nausea, vomiting and abdominal pain). Dynamic liver computed tomography (CT) or magnetic resonance (MR) imaging was conducted 4-8 weeks after the procedure. If the presence of residual viable tumors was confirmed or new lesions developed in patients with adequate liver function, further TACE procedures were carried out.

Baseline serum IGF-1 and VEGF determination. Peripheral venous blood samples $(5 \mathrm{ml})$ were collected prior to the first TACE procedure and centrifuged at $4^{\circ} \mathrm{C}$ for $25 \min (400 \mathrm{x} \mathrm{g})$. Serum samples were then collected and stored at $-20^{\circ} \mathrm{C}$ until used. Serum IGF-1 and VEGF levels were tested by an enzyme-linked immunosorbent assay (ELISA) method using Human IGF-1 and VEGF Quantikine ELISA kits (R\&D Systems, Minneapolis, $\mathrm{MN}, \mathrm{USA}$ ) according to the manufacturer's instructions.
Statistical analysis. Baseline continuous variables were presented as the mean \pm standard deviation (SD). Categorical variables were expressed as frequencies (percentages). The primary endpoint was time to progression (TTP), which was measured from the time of enrollment until tumor progression was first documented in imaging studies, in accordance with the modified Response Evaluation Criteria in Solid Tumors (mRECIST). The secondary endpoint was OS, which was defined as the time from enrollment to mortality. The association of clinical variables with TTP or OS was identified by univariate analysis with hazard ratios (HRs) and $95 \%$ confidence intervals (CIs), and variables with a $\mathrm{P}$-value less than 0.05 in the univariate analysis were then entered into stepwise Cox regression multivariate models. The Kaplan-Meier method was used to plot the TTP and OS curves and the log-rank test was used for comparison. Statistical analyses were performed using SPSS software, version 19.0 (IBM Corporation, Armonk, NY, USA). All tests were two-sided and $\mathrm{P}<0.05$ was considered statistically significant.

\section{Results}

Baseline characteristics and treatment response. Between May 2007 and June 2011, 145 patients with HCC who underwent TACE as initial treatment were eligible for this study. Baseline serum samples were available for 128 (88.3\%) of these patients. Various characteristics of the patients are listed in Table I. Of the 128 patients, 96 (75.0\%) were male, $103(80.5 \%)$ were positive for hepatitis B virus, $79(61.7 \%)$ had clinical liver cirrhosis, 88 (68.8\%) had Child-Pugh class A disease, and $122(95.3 \%)$ had elevated serum $\alpha$-fetoprotein (AFP) levels above the normal upper limit (>20 ng/ml). The median age at the time of diagnosis was 55 years (range, 38-76 years). The median size of the largest measurable lesion was $3.5 \mathrm{~cm}$ (range, 1.8-10.4 cm). According to the BCLC staging system, 7, 23, 67 and 31 patients were at stages $0, \mathrm{~A}, \mathrm{~B}$ and $\mathrm{C}$, respectively. During a median follow-up period of 47 months (range, 10.6-69.3 months), 98 patients (76.6\%) experienced disease progression with a median TTP of 7.5 months (range, 1.6-29.8 months). The overall cumulative progression rate in patients with $\mathrm{HCC}$ following TACE was $54.5,69.3$ and $78.4 \%$ after 1,2 and 3 years, respectively. The median survival time was 34.5 months (range, 5.8-69.3 months), with 59 of 128 patients (46.1\%) succumbing during the follow-up. The overall cumulative mortality rate was $19.3 \%$ after 1 year, $36.8 \%$ after 2 years and $44.7 \%$ after 3 years.

Association between clinical factors and expression of IGF-1 and VEGF. The associations between clinical factors and serum levels of IGF-1 and VEGF are presented in Table I. The serum IGF-1 level was found to be significantly associated with hepatitis infection status, Child-Pugh class, bilirubin level, tumor size and nodularity, vascular invasion and BCLC stage, with the Child-Pugh score having the strongest association ( $\mathrm{P}=0.003)$. The serum VEGF level was found to be significantly associated with the Child-Pugh class, tumor size, lymph node involvement and BCLC stage, with tumor size having the strongest association $(\mathrm{P}=0.009)$. 
Table I. Serum levels of IGF-1 and VEGF according to clinical characteristics of 128 patients with HCC undergoing TACE.

\begin{tabular}{|c|c|c|c|c|c|}
\hline \multirow[b]{2}{*}{ Characteristics } & \multirow[b]{2}{*}{ No. of patients (\%) } & \multicolumn{2}{|c|}{ IGF-1 (ng/ml) } & \multicolumn{2}{|c|}{ VEGF (pg/ml) } \\
\hline & & Mean $\pm \mathrm{SD}$ & P-value & Mean \pm SD & P-value \\
\hline Age, years & & & 0.385 & & 0.077 \\
\hline$<60$ & $73(57.0)$ & $61.3 \pm 33.8$ & & $269.5 \pm 77.8$ & \\
\hline$\geq 60$ & $55(43.0)$ & $56.4 \pm 37.4$ & & $281.6 \pm 99.4$ & \\
\hline Gender & & & 0.276 & & 0.316 \\
\hline Female & $32(25.0)$ & $62.1 \pm 38.1$ & & $267.4 \pm 79.8$ & \\
\hline Male & $96(75.0)$ & $55.2 \pm 43.1$ & & $279.3 \pm 83.2$ & \\
\hline Hepatitis infection status & & & 0.044 & & 0.059 \\
\hline HBV & $97(75.8)$ & $56.7 \pm 36.2$ & & $289.7 \pm 103.6$ & \\
\hline $\mathrm{HCV}$ & $14(10.9)$ & $58.4 \pm 39.4$ & & $278.1 \pm 85.4$ & \\
\hline $\mathrm{HBV}$ and $\mathrm{HCV}$ & $6(4.7)$ & $50.1 \pm 22.8$ & & $290.2 \pm 97.2$ & \\
\hline None & $11(8.6)$ & $63.0 \pm 27.5$ & & $265.4 \pm 81.1$ & \\
\hline Clinical cirrhosis & & & 0.093 & & 0.184 \\
\hline Present & $79(61.7)$ & $54.8 \pm 36.5$ & & $284.6 \pm 88.9$ & \\
\hline Absent & $49(38.3)$ & $60.2 \pm 39.7$ & & $270.3 \pm 81.2$ & \\
\hline Child-Pugh class & & & 0.003 & & 0.023 \\
\hline A & $88(68.7)$ & $63.4 \pm 41.2$ & & $264.3 \pm 77.2$ & \\
\hline $\mathrm{B}$ & $40(31.3)$ & $54.9 \pm 33.8$ & & $289.5 \pm 83.5$ & \\
\hline Bilirubin level, $\mu \mathrm{mol} / 1$ & & & 0.032 & & 0.458 \\
\hline$\leq 34$ & $92(71.9)$ & $64.1 \pm 38.6$ & & $271.6 \pm 73.4$ & \\
\hline$>34$ & $36(28.1)$ & $55.3 \pm 29.1$ & & $280.3 \pm 79.8$ & \\
\hline Serum AFP level, ng/ml & & & 0.087 & & 0.376 \\
\hline$<200$ & $97(75.8)$ & $60.4 \pm 37.8$ & & $268.2 \pm 75.6$ & \\
\hline$\geq 200$ & $31(24.2)$ & $56.2 \pm 33.6$ & & $284.1 \pm 80.3$ & \\
\hline Tumor size, $\mathrm{cm}$ & & & 0.005 & & 0.009 \\
\hline$<5 \mathrm{~cm}$ & $86(67.2)$ & $61.5 \pm 40.7$ & & $265.7 \pm 75.3$ & \\
\hline$\geq 5 \mathrm{~cm}$ & $42(32.8)$ & $52.9 \pm 30.6$ & & $288.3 \pm 82.1$ & \\
\hline Tumor nodularity & & & 0.025 & & 0.784 \\
\hline Uninodular & $90(70.3)$ & $60.3 \pm 38.9$ & & $275.1 \pm 76.2$ & \\
\hline Multinodular & $38(29.7)$ & $54.8 \pm 33.7$ & & $277.5 \pm 74.9$ & \\
\hline Vascular invasion & & & 0.017 & & 0.459 \\
\hline No & $104(81.2)$ & $61.7 \pm 36.4$ & & $271.7 \pm 71.2$ & \\
\hline Yes & $24(18.8)$ & $53.5 \pm 30.8$ & & $279.0 \pm 78.5$ & \\
\hline Lymph node involvement & & & 0.064 & & 0.036 \\
\hline No & $99(77.3)$ & $60.3 \pm 39.1$ & & $273.3 \pm 72.5$ & \\
\hline Yes & $29(22.7)$ & $55.8 \pm 34.3$ & & $289.1 \pm 82.1$ & \\
\hline BCLC stage & & & 0.011 & & 0.034 \\
\hline 0 & $7(5.5)$ & $61.8 \pm 22.6$ & & $267.1 \pm 66.1$ & \\
\hline A & $23(18.0)$ & $59.4 \pm 32.7$ & & $277.5 \pm 76.4$ & \\
\hline $\mathrm{B}$ & $67(52.3)$ & $52.7 \pm 35.4$ & & $287.3 \pm 81.5$ & \\
\hline $\mathrm{C}$ & $31(24.2)$ & $53.3 \pm 31.2$ & & $292.7 \pm 79.6$ & \\
\hline
\end{tabular}

AFP, $\alpha$-fetoprotein; BCLC, Barcelona Clinic Liver Cancer; HBV, hepatitis B virus; HCV, hepatitis C virus; HCC, hepatocellular carcinoma; IGF-1, insulin-like growth factor-1; SD, standard deviation; TACE, transarterial chemoembolization; VEGF, vascular endothelial growth factor.

Association of clinical factors with TTP and OS. Cut-off values for each of the clinical factors (including age and gender; Table II) were selected and univariate analysis was carried out to identify the factors significantly associated with TTP and OS. The results showed that high Child-Pugh score, larger tumor size, multiple tumors, vascular invasion, lymph node involve- 
Table II. Univariate and multivariate Cox analyses of clinical variables for time to progression.

\begin{tabular}{|c|c|c|c|c|}
\hline \multirow[b]{2}{*}{ Variables } & \multicolumn{2}{|c|}{ Univariate analysis } & \multicolumn{2}{|c|}{ Multivariate analysis } \\
\hline & $\mathrm{HR}(95 \% \mathrm{CI})$ & P-value & $\mathrm{HR}(95 \% \mathrm{CI})$ & P-value \\
\hline Age ( $\geq 60$ vs. $<60$ years) & $0.882(0.596-1.125)$ & 0.652 & & \\
\hline Gender (male vs. female) & $1.086(0.814-1.447)$ & 0.874 & & \\
\hline Hepatitis virus infection & & 0.348 & & \\
\hline $\mathrm{HBV}$ & $1.245(0.782-1.841)$ & & & \\
\hline $\mathrm{HCV}$ & $1.208(0.695-1.918)$ & & & \\
\hline $\mathrm{HBV}$ and $\mathrm{HCV}$ & $1.336(0.816-1.976)$ & & & \\
\hline None & 1.000 & & & \\
\hline Child-Pugh class (A vs. B) & $0.775(0.559-0.978)$ & 0.043 & $0.897(0.653-1.130)$ & 0.692 \\
\hline Bilirubin (>34 vs. $\leq 34 \mu \mathrm{mol} / \mathrm{l}$ ) & $1.122(0.846-1.492)$ & 0.890 & & \\
\hline $\operatorname{AFP}(\geq 200$ vs. $<200 \mathrm{ng} / \mathrm{ml})$ & $1.250(0.912-1.534)$ & 0.649 & & \\
\hline Tumor size ( $\geq 5$ vs. $<5 \mathrm{~cm}$ ) & $1.543(1.184-1.932)$ & 0.003 & $1.352(0.997-1.761)$ & 0.054 \\
\hline $\begin{array}{l}\text { Tumor nodularity } \\
\text { (uninodular vs. multinodular) }\end{array}$ & $1.327(1.095-1.570)$ & 0.022 & $1.287(0.952-1.534)$ & 0.061 \\
\hline Vascular invasion & $1.384(1.134-1.594)$ & 0.015 & $1.319(1.024-1.694)$ & 0.043 \\
\hline Lymph node involvement & $1.461(1.125-1.738)$ & 0.009 & $1.245(0.895-1.585)$ & 0.082 \\
\hline BCLC stage & & $<0.001$ & & \\
\hline 0 & 1.000 & & 1.000 & \\
\hline $\mathrm{A}$ & $1.934(1.447-2.586)$ & & $1.467(1.186-1.952)$ & 0.005 \\
\hline $\mathrm{B}$ & $2.213(1.602-2.884)$ & & $1.787(1.356-2.127)$ & $<0.001$ \\
\hline $\mathrm{C}$ & $2.675(1.937-3.361)$ & & $2.175(1.743-2.685)$ & $<0.001$ \\
\hline Serum IGF-1 (ng/ml) & $0.874(0.816-0.952)$ & 0.002 & $0.892(0.853-0.937)$ & $<0.001$ \\
\hline Serum VEGF (pg/ml) & $1.136(1.067-1.218)$ & 0.025 & 1.118 (1.048-1.192) & 0.031 \\
\hline
\end{tabular}

AFP, $\alpha$-fetoprotein; BCLC, Barcelona Clinic Liver Cancer; CI, confidence interval; HBV, hepatitis B virus; HCV, hepatitis C virus; HR, hazard ratio; IGF-1, insulin-like growth factor-1; VEGF, vascular endothelial growth factor.

ment and advanced BCLC stage were significantly associated with shorter TTP (all P<0.05). All the other selected factors (including age, gender and hepatitis virus infection) were not found to be significantly associated with TTP $(\mathrm{P}>0.05)$. In the multivariate analysis, BCLC stage and vascular invasion were independent risk factors for disease progression (Table II). When clinical factors were examined as potential independent risk factors for OS, only advanced BCLC stage was found to be significantly associated with poorer OS (Table III).

Association of IGF-1 levels with TTP and OS. The median serum IGF-1 value $(57.3 \mathrm{ng} / \mathrm{ml})$ was used as a cut-off in the univariate model and a low IGF-1 level $(<57.3 \mathrm{ng} / \mathrm{ml})$ was calculated to be associated with shorter TTP and poorer OS. In the multivariate analysis, IGF-1 was found to be an independent predictive factor for TTP and OS. The IGF-1 level was a stronger predictive tool when compared with VEGF, with a lower P-value (Table III). The median time to progression in patients with high IGF-1 levels was significantly longer than that in patients with low levels (Fig. 1A). The median survival time in patients with high IGF-1 levels was also significantly longer than that in patients with low IGF-1 levels (Fig. 1B).

\section{Discussion}

The prognosis of patients with $\mathrm{HCC}$ is poor, with a 5-year survival rate of $10 \%$ (16). Although the BCLC staging system and Cancer of the Liver Italian Program (CLIP) score are widely used for the guidance of treatment decisions and to stratify patients with HCC for clinical trials, patients within the same HCC stage in these HCC staging systems are notably heterogeneous (2). Biomarkers are expected to better predict patient survival and provide improved prognostic stratification. AFP has served as a diagnostic and prognostic marker for HCC for many years (17). However, persistent AFP elevation may be observed in some cirrhotic patients due to hepatocyte regeneration. Therefore, other markers, such as VEGF, hepatocyte growth factor (HGF) and transforming growth factor $\beta 1$ have been assessed as potentially improved diagnostic and prognostic predictors for HCC. However, absolute positive and negative markers for $\mathrm{HCC}$ remain deficient, and even those with very high sensitivity and specificity are not universally useful diagnostically (16). IGF-1 is a $7.6 \mathrm{kDa}$ single chain molecule with $\sim 50 \%$ identity to the sequences of the A- and B-chains of human insulin (18); it is produced primarily by the liver. IGF signaling plays an important role in growth promotion 
Table III. Univariate and multivariate Cox analyses of clinical variables for overall survival.

\begin{tabular}{|c|c|c|c|c|}
\hline \multirow[b]{2}{*}{ Variables } & \multicolumn{2}{|c|}{ Univariate analysis } & \multicolumn{2}{|c|}{ Multivariate analysis } \\
\hline & HR $(95 \% \mathrm{CI})$ & P-value & HR $(95 \% \mathrm{CI})$ & P-value \\
\hline Age ( $\geq 60$ vs. $<60$ years) & $0.769(0.603-1.092)$ & 0.348 & & \\
\hline Gender (male vs. female) & $1.143(0.786-1.549)$ & 0.864 & & \\
\hline Hepatitis virus infection & & 0.273 & & \\
\hline $\mathrm{HBV}$ & $1.291(0.659-1.754)$ & & & \\
\hline $\mathrm{HCV}$ & $1.180(0.783-1.651)$ & & & \\
\hline $\mathrm{HBV}$ and $\mathrm{HCV}$ & $1.381(0.832-1.903)$ & & & \\
\hline None & 1.000 & & & \\
\hline Child-Pugh class (A vs. B) & $0.832(0.595-1.087)$ & 0.083 & & \\
\hline Bilirubin (>34 vs. $\leq 34 \mu \mathrm{mol} / \mathrm{l}$ ) & $1.069(0.896-1.221)$ & 0.290 & & \\
\hline $\operatorname{AFP}(\geq 200$ vs. $<200 \mathrm{ng} / \mathrm{ml})$ & $1.145(0.917-1.365)$ & 0.184 & & \\
\hline Tumor size ( $\geq 5$ vs. $<5 \mathrm{~cm}$ ) & $1.476(1.189-1.841)$ & 0.004 & $1.362(0.982-1.754)$ & 0.0593 \\
\hline $\begin{array}{l}\text { Tumor nodularity } \\
\text { (uninodular vs. multinodular) }\end{array}$ & $1.293(0.974-1.615)$ & 0.059 & & \\
\hline Vascular invasion & $1.384(1.022-1.795)$ & 0.041 & $1.185(0.883-1.506)$ & 0.136 \\
\hline Lymph node involvement & $1.473(1.085-1.890)$ & 0.013 & $1.297(0.944-1.672)$ & 0.087 \\
\hline BCLC stage & & $<0.001$ & & \\
\hline 0 & 1.000 & & 1.000 & \\
\hline $\mathrm{A}$ & $1.592(1.225-1.931)$ & & $1.424(1.116-1.758)$ & 0.015 \\
\hline $\mathrm{B}$ & $1.874(1.416-2.385)$ & & $1.692(1.285-2.136)$ & $<0.001$ \\
\hline $\mathrm{C}$ & $2.136(1.775-2.587)$ & & $1.921(1.547-2.378)$ & $<0.001$ \\
\hline Serum IGF-1 (ng/ml) & $0.752(0.606-0.914)$ & 0.005 & $0.824(0.705-0.949)$ & 0.009 \\
\hline Serum VEGF (pg/ml) & $1.195(1.092-1.287)$ & 0.013 & $1.125(1.058-1.196)$ & 0.037 \\
\hline
\end{tabular}

AFP, $\alpha$-fetoprotein; BCLC, Barcelona Clinic Liver Cancer; CI, confidence interval; HBV, hepatitis B virus; HCV, hepatitis C virus; HR, hazard ratio; IGF-1, insulin-like growth factor-1; VEGF, vascular endothelial growth factor.

A

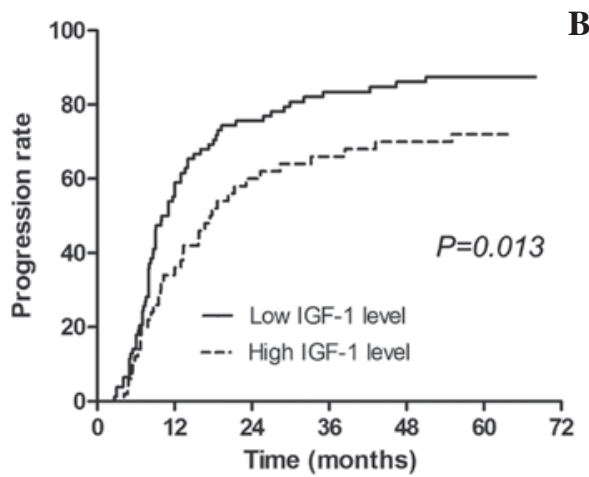

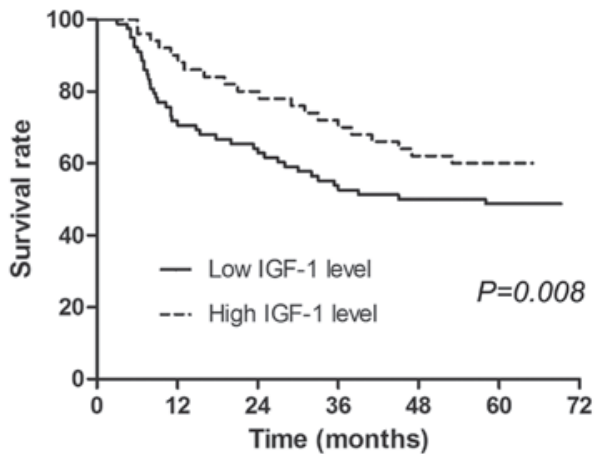

Figure 1. Kaplan-Meier estimates of (A) time to progression and (B) overall survival in patients with HCC following transarterial chemoembolization according the baseline levels of serum IGF-1. IGF, insulin-like growth factor; HCC, hepatocellular carcinoma.

in various tissues and organs, acting via autocrine, paracrine and endocrine mechanisms. Previous studies have shown that high baseline levels of IGF-1 in the serum are associated with an increased risk of cancer of the prostate, breast cancer, colon/rectum and lung (5-7,19). A number of studies have observed an association between IGF-1 and HCC. Kaseb et al found that lower plasma IGF-1 and higher plasma VEGF levels correlated significantly with advanced clinicopathological parameters and poor OS, and that when IGF-1 and VEGF were integrated into HCC staging, the prognostic stratification of patients was significantly enhanced (2). A recent study has also demonstrated that in patients with HCC, significant associations exist between IGF-1 expression and liver cirrhosis and survival (12). Similarly, Cho et al found that serum IGF-1 
levels correlated with OS in patients with HCC (20). However, another study evaluating the clinical utility of serum protein and mRNA levels of IGF-1 in HCC found that neither serum protein nor mRNA levels of IGF-1 are prognostic for the outcome of HCC patients (16). This finding warrants further investigation because it is based on a small sample size. In the current study, it was found that serum IGF-1 level was significantly associated with hepatitis infection status, Child-Pugh score, bilirubin, tumor size and nodularity, vascular invasion and BCLC stage. This is consistent with previous reports $(2,12)$, indicating that serum IGF-1 may be complementary to other clinical relevant prognostic indicators in patients with $\mathrm{HCC}$, including Child-Pugh score, tumor parameters and BCLC variables. Furthermore, a low IGF-1 level predicted shorter TTP and OS in patients treated with TACE. As serum IGF-1 is measured by a simple noninvasive approach, it may be widely used in clinical practice to aid the prognostic stratification of patients with HCC in clinical trials, which should help to guide treatment decisions and improve HCC outcomes.

Reduced circulating levels of IGF-1 in patients with hepatic cirrhosis or HCC have been attributed to liver damage as hepatocytes are the primary source of IGF-1 (21). The observation that IGF-1 synthesis is attenuated in chronic hepatitis $\mathrm{C}$ and reflects the severity of liver fibrosis appears to support this hypothesis (22). However, in the present study, the status of hepatitis infection but not the state of clinical liver cirrhosis was found to correlate with the serum IGF-1 levels. This may be due to the comparable liver functions of the patients enrolled in this study. Although the majority of the patients in the present study had Child-Pugh class A liver function, the levels of IGF-1 served to predict progression and mortality, regardless of the remnant liver function. Therefore, the serum levels of IGF-1 may be considered in addition to other parameters, such as Child-Pugh class or BCLC stage, to aid the assessment of hepatic function and prognostically evaluate patients with HCC (20).

In conclusion, the present study shows that the baseline serum IGF-1 level correlated with clinical factors of patients with HCC and was an independent predictive factor for TTP and OS. The results suggest that serum IGF-1 may serve as a novel factor for use in determining the prognosis of patients with HCC undergoing TACE.

\section{Acknowledgements}

The authors thank International Science Editing for language editing work on this manuscript.

\section{References}

1. Jemal A, Bray F, Center MM, Ferlay J, Ward E and Forman D: Global cancer statistics. CA Cancer J Clin 61: 69-90, 2011.

2. Kaseb AO, Morris JS, Hassan MM, Siddiqui AM, Lin E, Xiao L, Abdalla EK, Vauthey JN, Aloia TA, Krishnan S and Abbruzzese JL: Clinical and prognostic implications of plasma insulin-like growth factor-1 and vascular endothelial growth factor in patients with hepatocellular carcinoma. J Clin Oncol 29: 3892-3899, 2011.

3. Ziol M, Sutton A, Calderaro J, Barget N, Aout M, Leroy V, Blanc JF, Sturm N, Bioulac-Sage P, Nahon P, et al: ESM-1 expression in stromal cells is predictive of recurrence after radiofrequency ablation in early hepatocellular carcinoma. J Hepatol 59: 1264-1270, 2013.
4. Maki RG: Small is beautiful: Insulin-like growth factors and their role in growth, development and cancer. J Clin Oncol 28: 4895-4995; 2010.

5. Chan JM, Stampfer MJ, Giovannucci E, Gann PH, Ma J, Wilkinson P, Hennekens CH and Pollak M: Plasma insulin-like growth factor-I and prostate cancer risk: A prospective study. Science 279: 563-566, 1998.

6. Hankinson SE, Willett WC, Colditz GA, Hunter DJ, Michaud DS, Deroo B, Rosner B, Speizer FE and Pollak M: Circulating concentrations of insulin-like growth factor-I and risk of breast cancer. Lancet 351: 1393-1396, 1998.

7. Ma J, Pollak MN, Giovannucci E, Chan JM, Tao Y, Hennekens CH and Stampfer MJ: Prospective study of colorectal cancer risk in men and plasma levels of insulin-like growth factor (IGF)-I and IGF-binding protein-3. J Natl Cancer Inst 91: 620-625, 1999.

8. Elsammak MY, Amin GM, Khalil GM, Ragab WS and Abaza MM: Possible contribution of serum activin A and IGF-1 in the development of hepatocellular carcinoma in Egyptian patients suffering from combined hepatitis $\mathrm{C}$ virus infection and hepatic schistosomiasis. Clin Biochem 39: 623-629, 2006.

9. García-Galiano D, Sánchez-Garrido MA, Espejo I, Montero JL, Costán G, Marchal T, Membrives A, Gallardo-Valverde JM, Muñoz-Castañeda JR, Arévalo E, et al: IL-6 and IGF-1 are independent prognostic factors of liver steatosis and non-alcoholic steatohepatitis in morbidly obese patients. Obes Surg 17: 493-503, 2007.

10. Luo SM, Tan WM, Deng WX, Zhuang SM and Luo JW: Expression of albumin, IGF-1, IGFBP-3 in tumor tissues and adjacent non-tumor tissues of hepatocellular carcinoma patients with cirrhosis. World J Gastroenterol 11: 4272-4276, 2005.

11. Su WW, Lee KT, Yeh YT, Soon MS, Wang CL, Yu ML and Wang SN: Association of circulating insulin-like growth factor 1 with hepatocellular carcinoma: One cross-sectional correlation study. J Clin Lab Anal 24: 195-200, 2010.

12. Chun YS, Huang M, Rink L and Von Mehren M: Expression levels of insulin-like growth factors and receptors in hepatocellular carcinoma: A retrospective study. World J Surg Oncol 12: 231, 2014.

13. Shao YY, Huang CC, Lin SD, Hsu CH and Cheng AL: Serum insulin-like growth factor-1 levels predict outcomes of patients with advanced hepatocellular carcinoma receiving antiangiogenic therapy. Clin Cancer Res 18:3992-3997, 2012.

14. Bruix J and Sherman M: American association for the study of liver diseases: Management of hepatocellular carcinoma: An update. Hepatology 53: 1020-1022, 2011.

15. American Association for the Study of Liver Diseases: Management of Hepatocellular Carcinoma: An Update. http://www.aasld.org/publications/practice-guidelines-0. Accessed September 16, 2014.

16. Karabulut S, Duranyildiz D, Tas F, Gezer U, Akyüz F, Serilmez M, Ozgür E, Yasasever CT, Vatansever S and Aykan NF: Clinical significance of serum circulating insulin-like growth factor-1 (IGF-1) mRNA in hepatocellular carcinoma. Tumour Biol 35: 2729-2739, 2014.

17. Malaguarnera G, Giordano M, Paladina I, Berretta M, Cappellani A and Malaguarnera M: Serum markers of hepatocellular carcinoma. Dig Dis Sci 55: 2744-2755, 2010.

18. De Mellow JS and Baxter RC: Growth hormone-dependent insulin-like growth factor (IGF) binding protein both inhibits and potentiates IGF-I-stimulated DNA synthesis in human skin fibroblasts. Biochem Biophys Res Commun 156: 151-156, 1988.

19. Yu H, Spitz MR, Mistry J, Gu J, Hong WK and Wu X: Plasma levels of insulin-like growth factor-I and lung cancer risk: A case-control analysis. J Natl Cancer Inst 91: 151-156, 1999.

20. Cho E, Kim HC, Lee JH, Yoo JJ, Choi WM, Cho YY, Lee MJ, Lee YB, Yu SJ, Kim YJ, et al: Serum insulin-like growth factor-1 predicts disease progression and survival in patients with hepatocellular carcinoma who undergo transarterial chemoembolization. PLoS One 9: e90826; 2014.

21. Mazziotti G, Sorvillo F, Morisco F, Carbone A, Rotondi M, Stornaiuolo G, Precone DF, Cioffi M, Gaeta GB, Caporaso N and Carella C: Serum insulin-like growth factor I evaluation as a useful tool for predicting the risk of developing hepatocellular carcinoma in patients with hepatitis $\mathrm{C}$ virus-related cirrhosis: $\mathrm{A}$ prospective study. Cancer 95: 2539-2545, 2002.

22. Lorenzo-Zúñiga V, Bartolí R, Masnou H, Montoliu S, Morillas RM and Planas R: Serum concentrations of insulin-like growth factor-I (igf-I) as a marker of liver fibrosis in patients with chronic hepatitis C. Dig Dis Sci 52: 3245-3250, 2007. 